\title{
Sınıf Öğretmenlerinin Birey-Örgüt Uyumu Üzerine Bir Araştırma ${ }^{1}$
}

\author{
DOI: $10.26466 /$ opus.567443
}

\author{
Volkan Sarıboğa* - Elife Doğan Kılıç** - Hüseyin Serin ${ }^{* * *}$ \\ *Öğretmen. Milli Eğitim Bakanlığı İstanbul Nevin Mehmet Bilginer İlkokulu, İstanbul/ Türkiye \\ E-Posta: volkansariboga1@gmail.com \\ ORCID: $\quad$ 0000-0001-7453-4003 \\ **Prof.Dr., İstabul Üniversitesi-Cerrahpaşa,Hasan Ali Yücel Eğitim Fak. İstanbul/ Türkiye \\ E-Posta: ekilic@istanbul.edu.tr \\ ORCID: $0000-0002-6751-9259$ \\ *** Dr. Öğr. Üyesi, İstabul Üniversitesi-Cerrahpaşa,Hasan Ali Yücel Eğitim Fak. İstanbul/ Türkiye \\ E-Posta: huseyin.serin@istanbul.edu.tr \\ ORCID: $\quad \underline{0000-0003-3002-8787}$
}

\section{Öz}

Bu araştırmanın amacı ilkokullarda görev yapan sinıföğretmenlerinin birey-örgüt uyumu konusundaki görüşlerini belirlemektir. Araştırmanın evreni İstanbul ili Bağcllar ilçesindeki ilkokullarda görev yapan sınıf öğretmenlerinden oluşmaktadır. Araştırmanın örneklemini ise Bă̆cllar'da yer alan ilkokullarda görev yapan ve evrenden random olarak seçilen gönüllü 153 sinıf öğretmeni oluşturmaktadır. Araştırmada Netemeyer ve diğerleri (1997) tarafindan geliştirilen, Turunç ve Çelik (2012) tarafindan Türkçe'ye uyarlanmış olan Birey-Örgüt Uyumu ölçeğgi kullanılmıştır. Dört maddeden oluşan bu ölçeğin Cronbach $(\alpha)$ değeri 0,94 olarak belirlenmiştir. Birey-örgüt uyumu ölçeğinden elde edilen verilerin istatistiksel analizi yapılmıştır. Sinıföğretmenlerinin birey-örgüt uyumuna ilişkin görüşlerinin cinsiyet ve kıdem değişkenleri açısından anlamlı bir farklılık gösterip göstermediği iki yönlü varyans (two-way ANOVA) analiziyle incelenmiştir. Analiz öncesinde varyans analizi varsayımlarından 'alt gruplarm herbiri için verilerin normal şekilde dağıllıp dağglmaması' ve 'gruplar arasındaki varyansların homojen olması ya da olmaması' gibi varsayımlar test edilmiştir. Levene testi, verilerin normal dağıllip dağılmama durumunu ortaya koymak için tercih edilmiştir. Araştırmada, ilkokullarda görev yapan sinıfö̆gretmenlerinin birey- örgüt uyumu konusundaki görüşlerinde cinsiyet ve kıdem değişkenlerine göre anlamlı bir farklılık bulunmadı̆̆ı sonucuna ulaşılmıştır.

Anahtar Kelimeler: Birey-örgüt uyumu, değerler, ihtiyaçlar

\footnotetext{
${ }^{1}$ Bu çalışmanın bir bölümü ERPA INTERNATIONAL CONGRESS on Education'da (28 Haziran-1 Temmuz 2018) sözlü bildiri olarak sunulmuştur.
} 


\title{
A Research on Person-Organization Fit of Primary School Teachers
}

\begin{abstract}
The aim of this research is to determine the views of primary school teachers on person-organization fit. The population of the research consists of primary school teachers who work in Bağcllar district of Istanbul. The sample of the research is consists of 153 volunteer primary school teachers who were randomly selected from the population. In the research, the scale of 'Person-Organization Fit' which was developed by Netemeyer et al. (1997) and adapted to Turkish by Turunç and Çelik (2012) was used. Person-Organization Fit' scale consists of 4 items. The Cronbach alpha value of the scale was determined as 0,94. Data obtained from the person-organization fit scale were statistically analysed. Two-way ANOVA was used to determine whether person-organization fit showed a significant difference in teachers' views according to gender and seniority variables. Before the analysis, such variance analysis assumptions were tested as whether the data were normally distributed for each subgroup and whether the variances were homogeneous between the groups. Levene test was used to determine whether the data were normally distributed or not. The research results indicate that the opinions of primary school teachers about person-organization fit did not show a significant difference according to seniority and gender variables.
\end{abstract}

Keywords: Person-Organization Fit, Values, Needs. 


\section{Giriş}

Bir örgüte giren bireyin amaçları bazen örgütün amaçları ile uyuşurken bazen de uyuşmayabilmektedir. Bu açıdan bireyin amaçları, örgütün amaçlarını gerçekleştirebilmek için bir araç olmalı ve birey ile örgüt arasindaki uyumu bozmamalıdır (Baysal, 1985). Bu nedenle 21. yüzyılda birey ve örgütün uyumluluk düzeyi, işgören seçim kararlarında önemini artırmaya başlayan bir ölçüt olmaktadır (Rynes vd., 2002).

Modern örgütlerin temel hedeflerinden biri işgörenlerin işe ve örgüte uyumunu sağlamaktır. Birey-örgüt uyumunu gerçekleştiren işgörenlerin bireysel ve örgütsel ölçüde daha verimli ve mutlu olacağ1 düşünülmektedir. Yaşadığı ortama uyum sağlayabilen ve yaşadığı ortamı benimseyen işgörenlerin bireysel, örgütsel ve toplumsal katkıları artmaktadır (Van Vianen vd., 2007). Örgütlerde, işe alım sürecinde örgüte uyum sağlayabilecek bireylerin seçimine özen gösterilmekte ve aynı şekilde işe yeni alınan bireylere oryantasyon programları düzenlenerek işgörenlerin sosyalizasyonunun gerçekleştirilmesi hedeflenmektedir (Kesen, 2017). Örgütsel sosyalizasyon, işgörenlerin yeni katıldıkları örgütte örgütsel kuralları, normları, kültürü öğrenmek ve rolleri yerine getirmek amacı için gereken teknik becerileri öğrendikleri bir süreçtir (Çalık, 2003). Birey-örgüt uyumu, örgütlerin amaçlarına ulaşmada önemli araçlardan biridir. Uyum sağlamış ve işgörenlerinin temel amaçlarına yönelmiş bir örgüt, uyumun verimlilik gibi olumlu sonuçlarından yararlanır. Uyumsuzluk durumunda ise, işgörenlerde artan iş stresi verimsizliğe yol açarak örgütün amaçlarına ulaşmasının önünde büyük bir engel oluşturabilir (Ulutaş, 2011). Bireyörgüt uyumu konusunda, Schneider (1987) tarafından ileri sürülen ASA (çekim-seçim-çekişme) teorisi çeşitli açıklamalar sunmaktadır. Bu teoriye göre işgörenler kendi değerlerine, ihtiyaçlarına ve kişiliğine uygun örgütlere yönelmektedir (Yıldız, 2013). Schneider (1987), bireylerin kendileriyle benzer özellik taşıyan bireylerin bulunduğu örgütlerde daha rahat hissettiklerini, sonuç olarak bu tarz örgütlere katılım göstermede daha istekli olduklarını ileri sürmektedir. Örgütler de örgüt kültürüne daha uygun olan bireyleri tercih etmektedir. İşören örgüte girdikten sonra, hem birey hem de örgüt bu uygunluk durumunu sürdürme eğilimi gösterirken; ör- 
güt ise bireylerin örgütsel gelenek ve değerlere uyumlarını sağlamak amacıyla sosyalizasyon sürecini işletmektedir (Ulutaş, Kalkan ve Bozkurt, 2015).

Birey-örgüt uyumu, araştırmacılar tarafından çeşitli şekillerde tanımlanmaktadır. Chatman (1989) bu kavrami; normlar ve değerler ile bireysel değerlerin uyumu olarak tanımlarken, Kristof (1996) ise "bireyin beklentisinin, isteğinin, kişisel değerlerinin ve amaçlarının örgütün değer, amaç ve sistemine uygunluğu" olarak ifade etmektedir. Andrews, Baker ve Hunt (2011)'a göre ise birey-örgüt uyumu; bireyin kişiliği, değerleri, amaçları, tutumları ile örgütsel kültür, değer, amaç ve normlar arasındaki uyumdur. Birey-örgüt uyumu kişilik, değer ve ihtiyaç kavramlarının siniflandırılmasına dayanmaktadır (Van Vianen, 2001). Chatman (1989) birey-örgüt uyumunu, 'kişisel ve örgütsel değerler ile normların ya da bireysel ve örgütsel değerlerin arasındaki uygunluk durumu' olarak ifade etmiştir. Kristof (1996) ise birey-örgüt uyumunu 'bireyin beklentisinin, isteğinin, kişisel değerlerinin ve amaçlarının örgütün değerlerine, amaçlarına ve sistemine uygunluğu' olarak tanımlamıştır. Schneider (1987)'in Çekim-Seçim-Çekişme (ASA) teorisinde ileri sürdüğü bireyin kendi değer, ihtiyaç ve kişiliğine uygun örgütlere yöneldiği düşüncesi, Chatman (1989) ve Kristof (1996)'un birey-örgüt uyumuna ilişkin görüşleriyle ortak noktalara sahiptir. Chatman'in birey-örgüt uyumunu kişisel değerler ve örgütsel değerler ile normlar arasındaki uygunluk olarak tanımlaması, Kristof'un da benzer şekilde değer kavramına vurgu yapması değerlerin birey-örgüt uyumunun sağlanmasında önemli bir işleve sahip olduğunu göstermektedir. Schneider (1987)'in ASA teorisinde birey-örgüt uyumunun sağlanmasına dair ilk öğe bireysel ve örgütsel değerlerin uyumudur. Bireylerin düşünce, tutum ve davranışlarını etkileyen kültürel öğeler 'değer' olarak adlandırılır (Fidan, 2009). Bireysel değerler, herhangi bir topluluğun kendine has birliğini, sürekliliğini ve varlığını devam ettirme amacı doğrultusunda üyelerin genelinin doğru olduğuna inandığı; topluluğun amaç, duygu ve düşüncelerini gösteren inanış ya da ilkelerdir (Demirci ve Aydemir, 2006). Örgütte davranışlardan hangilerinin iyi hangilerinin kötü karşılandığına dair işgörenlerin ortak değerleri vardır (Özkalp ve Kırel, 2001). Örgütsel değerler, örgütte genel kabul gören durum ve davranışları ifade eder (Chatman, 1991). Örgütsel değerler, işgörenlerin 
doğruyu fark edebildiği veya tercihlerin ve neticelerin önemliliğini öngörebildiği, iş veya çalışma çevresiyle ilgili değerlendirme standartlarıdır (Vurgun ve Öztop, 2011). Bireysel değerlerin örgütsel değerlerle uyumu, işgörenlerin iş davranışlarının niteliğini belirlemede etkilidir (Kılıç, 2010). Schneider (1987)'a göre ihtiyaçlar da, birey-örgüt uyumunu belirlemede ikinci önemli öğedir. Bireysel ihtiyaçlar konusunda Maslow (1970), Herzberg (1982), Alderfer (Newstorm Keith, 1997), McClelland (Hodgetts ve Luthans, 1994) gibi araştırmacılar çeşitli teoriler ortaya koymaktadır. Maslow 'İhtiyaçlar Hiyerarşisi'; Herzberg 'Hijyen'; Alderfer 'ERG' (existincerelatedness- growth) ve McClelland 'Başarı İhtiyaci' teorileri ile bireylerin ihtiyaçlarını ve bu ihtiyaçların karşılanması ya da karşılanamaması durumunda ortaya çıkan sonuçları incelemekte, bu konuda fikirler ileri sürmektedir. Örneğin İhtiyaçlar Hiyerarşisi teorisinde, Maslow bireyin ihtiyaçlarının belirli bir sıraya göre karşılanması gerektiğini ileri sürmektedir. Hiyerarşideki ihtiyaçlar alt basamaktan üst basamağa doğru 'fizyolojik, güvenlik, ait olma ve sevgi, takdir edilme ve saygı, kendini gerçekleştirme' ihtiyaçları olarak sıralanmaktadır (Hoy ve Miskel, 2013). Bu teoriye göre bireyin bir üst basamağa geçebilmesi alt basamaktaki ihtiyaçların yeterli seviyede karşılanmasıyla mümkündür (Kula ve Çakar, 2015). Örgütsel ihtiyaçlar ise örgütsel bağlılık, çalışkanlık, işgörenlerin iş birliği, yaratıcılık, emirlere uyma, kaliteli iş, örgütsel amaçlara bağlılık, diğger işgörenler ile dostluk, otoriteye saygı ve işgören doyumu gibi örgütün türüne ve amaçlarına göre değişen ihtiyaçlardan oluşmaktadır (Ulutaş, 2011). Schneider (1987)'in birey-örgüt uyumunun sağlanmasında ele aldığı üçüncü öğe kişiliktir. Kişilik; bireyi diğerlerinden farklılaştıran ve sosyal ilişkiler boyutunda gözlemlenebilme olanağı olan işlevsel, ruhsal ve bedensel özellikler bütünüdür (Soysal, 2008). Bireyin kişiliğinin yanında örgütün de kendine özgü bir kişiliği vardır (Bursalığlu, 2015). Netemeyer ve diğ. (1997) yaptıkları araştırmada 'adaleti' birey-örgüt uyumunun sağlanması için gereken öğelerden biri olarak belirtmişlerdir. Birey- örgüt uyumunun gerçekleşmesi için, bireyin adalet algısı ile örgütün adalet algısının uyumlu olması gerekmektedir (Tutar, 2014). Adaletin sağlandığı örgütte, işgörenler üstlerinin davranışlarını eşit, ahlâka uygun, akılcı bulurlar. İşgörenlerin örgütteki yöntemlerin ve işlemlerin adalete uygunluğu hakkındaki düşünceleri, örgütlerine duydukları bağlılık ve inancı değiştirmektedir (Özgen ve Turunç, 2017). 
Bu bilgiler ışığı altında birey- örgüt uyumu ile ilgili alanyazın incelemesi yapıldığında birey-örgüt uyumu ile ilgili değişik alanlarda değişik çalışmalara rastlanmaktadır. Muhasebe alanında çalışan 171 kişi ile gerçekleştirilen çalışmada birey-örgüt uyumu ile iş tatmini arasında 0,05 anlamlılık düzeyinde 0,35'lik bir ilişki tespit edilmiştir (Chatman, 1991). Bir başka çalışma ise taşımacılık sektöründe orta ve üst düzey yönetici pozisyonunda istihdam edilen 387 özel sektör çalışanı ile gerçekleştirilmiştir. $\mathrm{Bu}$ araştırmada birey-örgüt uyumu düzeylerine göre işgörenlerin iş tatmini düzeylerinde farklılıkların olduğu gözlenmiştir (Boxx vd. 1991). Netemeyer vd. (1997) ödül dağıtımında adalet, örgütsel vatandaşlık davranışı, lider desteği, iş tatmini ve birey-örgüt uyumu arasındaki ilişkileri tespit etmek amacıyla bireysel ve kurumsal müşterilere mesajlaşma hizmeti pazarlayan 91 satış personeli üzerinde gerçekleştirdikleri birinci çalışmada iş tatmini ve birey-örgüt uyumu arasındaki anlamlı ilişkinin \%77 düzeyinde; e-mail yoluyla ulaştıkları 182 satış personeli ile gerçekleştirdikleri ikinci çalışmada ise \%50 düzeyinde olduğunu tespit etmişlerdir. Vilela vd. (2008), satış denetleyicisi ve satış personeli üzerinde gerçekleştirdikleri çalışmada iş tatmini ve birey örgüt uyumunun 0,67 düzeyinde anlamlı bir ilişki gösterdiğini ortaya koymuşlardır. Song ve Chathoth (2011), 381 katılımcidan elde ettikleri veriden hareketle gerçekleştirdikleri çalışmada birey-örgüt uyumu ve iş tatmini arasında \%35,3 düzeyinde anlamlı ilişki tespit etmişlerdir. 100 mavi ve beyaz yakalı çalışan iki yıl süresince, işe girişte ve işe girişten sonraki 6. ve 18. ay olarak üç aşamada gözlemlenerek bir araştırma yapılmıştır. Bu araştırmada birey-örgüt uyumu ve örgütsel bağlılığın pozitif yönde sebep-sonuç ilişkisi gösterdiği tespit edilmiştir (Saraç ve Meydan, 2013). Şerefhanoğlu (2014) ise uyum süreçleri ve okul müdürlerinin mentorluk fonksiyonları ilişkisinin belirlenmesine yönelik bir araştırma yapmıştır. Bu araştırmada evreni, 2012-2013 eğitim-öğretim yılı içinde Balıkesir ilinde yer değiştiren 960 öğretmen oluşturmuştur. Araştırma sonucunda okul müdürlerinin mentorluk fonksiyonları ve öğretmenlerin örgütsel uyum süreçleri ilişkisinin orta düzeyde $(, 608)$ olduğu belirlenmiştir. Ayrıca okul müdürlerinin mentorluk fonksiyonlarının arttıkça öğretmenlerin örgütsel uyum düzeylerinin artış gösterdiği görülmüştür. Alanyazında yapılan incelemelerde birey-örgüt uyumu konusunda yapılan çalışmaların daha çok işletmelere yönelik olduğu görülmektedir. Bunun yanı sıra eğitim alanında birey-örgüt uyumu 
ile ilgili çalışmaların iş tatmini, örgütsel bağlılık, mentorluk gibi boyutlar açısından ele alındığı tespit edilmiştir.

$\mathrm{Bu}$ araştırmanın amacı ise, birey-örgüt uyumu konusunda sınıf öğretmeni görüşlerinin kıdem ve cinsiyet değişkenleri açısından değişiklik gösterip göstermediğini belirlemektir.

\section{Yöntem}

Bu araştırmada kullanılan araştırma modeli ilişkisel taramadır. Bu model, iki veya ikiden fazla değişken arasındaki değişimin varlığını veya düzeyini belirlemek için kullanılır.

Tarama araştırmalarında genel olarak araştırmacının ölçekte belirlediği cevap seçenekleri aracılığıyla büyük bir kütleden veri toplanır ve araştırmacılar, görüşlerin ve niteliklerin kaynaklanma sebeplerinden daha çok örneklemde yer alan katılımcılara nasıl dağıldığına ilgi gösterirler (Fraenkel ve Wallen, 2009). Bu nedenle ilişkisel tarama modeli, genel tarama yöntemi içinde bulunmaktadır. Genel tarama modelleri; eleman sayısının fazla olduğu bir evren hakkında genel yargıya ulaşmak amacıyla evrenin hepsinde veya evrenden alınabilecek örnek ya da örneklem üzerinde gerçekleştirilen tarama düzenlemeleri olarak tanımlanabilir (Karasar, 2006). 2018-2019 eğitim-öğretim yılı süresince İstanbul ili Bağcclar ilçesinde bulunan ilkokullarda görev yapan sınıf öğretmenleri, bu araştırmada evreni oluşturmuştur. Araştırmanın örneklemi ise evrenden random olarak seçilen gönüllü 153 sinıf öğretmeninden oluşmuştur.

Araştırma, 2018-2019 eğitim-öğretim yılı İstanbul ili Bağcllar ilçesindeki ilkokullarda görev yapan ve araştırmaya gönüllü olarak katılan sınıf öğretmenlerinin görüşleriyle; 2018-2019 eğitim-öğretim yılındaki veri ve durumlarla sinırlıdır.

$\mathrm{Bu}$ araştırmada, birey-örgüt uyumu konusunda öğretmenlerin görüşlerini belirlemek için Netemeyer ve diğ.nin (1997) geliştirdiği ve Türkçeye Turunç ve Çelik (2012) tarafından uyarlanan “Birey-Örgüt Uyumu” ölçeği kullanılmıştır. Ölçek 4 maddeden oluşmuş ve 5'li Likert tarzında tasarlanmıştır. Ölçekteki ifadelerden "hiç katılmıyorum" 1, "çoğunlukla katılmiyorum" 2, "orta düzeyde katılıyorum" 3, "çoğunlukla katılıyorum" 4 ve "kesinlikle katılıyorum" 5 olarak puanlanmıştır. Ölçeğin güvenilirli- 
ğini belirlemeye ilişkin olarak Cronbach $(\alpha)$ kullanılmış ve analiz neticesinde Cronbach $(\alpha)=0,88$ olarak tespit edilmiştir. Turunç ve Çelik (2012) tarafından yapılan Türkçe uyarlama çalışmasında ise Cronbach $(\alpha)$ değeri 0,81 olarak hesaplanmıştır. Bu araştırmada ise araştırmacılar tarafından yapılan analiz ile Cronbach $(\alpha)=0,94$ olarak belirlenmiştir. Bu katsayı; 0,80 ve 1,00 değerleri arasında olduğunda güvenilirlik düzeyinin yüksek olduğu kabul edilmektedir (Özdamar, 2013).

Söz konusu ölçeğin yapı geçerliliğini tespit etmek amacıyla faktör analizi uygulanmıştır. SPSS 21 Paket programına veriler yüklendikten sonra 4 maddenin oluşturduğu ölçeğin faktör yapısının veri analiz yollarından biri olan Temel Bileşenler Analizi ile tespit edilmesi amaçlanmıştır. Analizin faktör sayısına ilişkin bir tespit ya da etkide bulunulmayarak faktörler serbest bırakılmıştır. Analiz neticesinde Kaiser-Meyer Olkin (KMO) değerinin ,83 olduğu görülmüş ve öz değeri 1,00'den yüksek olan dört maddenin tümü ölçeğe dahil edilmiştir. Ölçeğin birbiriyle bağımsız olan alt faktörlerini tespit etmek için varimax dik döndürme yöntemi seçilmiş ve faktör yüklerinin alt kesme noktasının değeri 0,35 olarak belirlenmiştir. Ölçekte yer alan maddelerden birincinin toplam varyansın \%84,602'sini, ikincinin \% 8,050'sini, üçüncünün \%3,743'ünü, dördüncünün ise \%3,605'ini açıkladığı tespit edilmiştir. Yapılan faktör analizi sonucunda ölçek tek boyutlu olarak belirlenmiştir. Ölçeği oluşturan maddelerin faktör yük değerlerinin .898 ile .938 arasında yer aldığı görülmüştür.

153 sınıf öğretmeninin görüşü, birey-örgüt uyumu ölçeğinden elde edilen verilerle istatistiksel olarak analiz edilmiştir. Birey- örgüt uyumu konusunda cinsiyet ve kıdem değişkenine göre öğretmen görüşleri arasında anlamlı bir farklılık olup olmadığını belirleyebilmek için iki yönlü varyans analizi (two-way ANOVA) kullanılmıştır. Analiz öncesinde varyans analizi varsayımlarından 'alt grupların herbiri için verilerin normal şekilde dağılıp dağılmaması' ve 'gruplar arasındaki varyansların homojen olması ya da olmaması' gibi varsayımlar test edilmiştir. Levene testi, verilerin normal dağılıp dağılmama durumunu ortaya koymak için tercih edilmiştir. Analizler neticesinde, verilerin normal dağıldığı görülmüştür.

$\mathrm{Bu}$ araştırmada eta-kareden (etki büyüklüğü) bağımsız değişkenin bağımlı değişken üzerindeki etkililik derecesini görmek amacıyla yararlanılmıştır. Büyüköztürk (2006), eta-karenin (†2) değişkenler arasındaki doğ- 
rusallık varsayımını gerektirmediğini ve bağımsız değişkenin bağımlı değişken üzerindeki etkililik düzeyini gösterdiğini açılamıştır. Etki büyüklügü (effect size) olarak isimlendirilen $\eta 2$, faktörün veya bağımsız değişkenin bağımlı değişkendeki toplam varyansın ne kadarını açıklayabildiğini ortaya koymaktadır. Büyüköztürk (2006), eta-karenin 0.00 ve 1.00 değerleri arasında değişmekte olduğunu ve $.01, .06$ ve .14 seviyesindeki $\eta 2$ değerlerinin sırasıyla göre "küçük", "orta", "geniş" şeklinde yorumland1ğını belirtmiştir.

Yapılan iki yönlü varyans analizi $\mathrm{p}<0.05$ anlamlllık düzeyinde kabul edilmiştir. Araştırmada yer alan öğretmenlerin Birey- Örgüt Uyumu Ölçeğinin 5'li likert seçeneklerinde işaretledikleri puan aralıkları belirlenmeye çalışılmıştır. Bu puan aralığı için aşağıdaki formül kullanılmıştır (Kaplanoğlu, 2014). Puan aralığı = En Yüksek Değer- En Düşük Değer /5 $=(5-1) / 5=0,80^{\prime}$ dir.

Tablo 1. 5'li Likert Ölçeğine Göre Aritmetik Ortalamalarının Değerlendirilmesi

\begin{tabular}{ll}
\hline Aralık & Seçenek \\
\hline $\mathbf{1 . 0 0 - 1 , 8 0}$ & Hiç katılmıyorum. \\
$\mathbf{1 , 8 1 - 2 , 6 0}$ & Çoğunlukla katılmıyorum. \\
$\mathbf{2 , 6 1 - 3 , 4 0}$ & Orta düzeyde katıllyorum. \\
$\mathbf{3 , 4 1 - 4 , 2 0}$ & Çoğunlukla katıllyorum. \\
$\mathbf{4 , 2 1 - 5 , 0 0}$ & Tamamen katıllyorum. \\
\hline
\end{tabular}

\section{Bulgular}

Tablo 2'de, sınıf öğretmenlerinin cinsiyet ve mesleki kıdem değişkenlerine göre dağılımları yer almaktadır.

Tablo 2. Araştırmaya Katılan Sınıf Öğretmenlerinin Demografik Bilgilerinin $f$ ve \% Dağılımları

\begin{tabular}{llll}
\hline Değişkenler & & f & \% \\
\hline \multirow{3}{*}{ Cinsiyet } & Kadın & 112 & 73,2 \\
& Erkek & 41 & 26,8 \\
& Toplam & 153 & 100 \\
\hline \multirow{3}{*}{ Kıdem } & $1-5$ yll & 22 & 14,4 \\
& $6-10$ yıl & 25 & 16,3 \\
& $11-15$ yıl & 35 & 22,9 \\
& $16+$ yıl & 71 & 46,4 \\
& Toplam & 153 & 100 \\
\hline
\end{tabular}


Tablo 2'de görüldüğü gibi, araştırma \%73,2 kadın, \%26,8 erkek sınıf öğretmeninden oluşmaktadır ve öğretmenlerin \%14,4'ü 1-5 yıl, \% 16,3'ü 6-10 yıl , \% 22,9'u 11-15 yıl ve \% 46,4'ü 16+ yıl kıdeme sahiptir. Araştırmaya katılanların \% 70'den fazlası kadın öğretmenlerden oluşurken, yine araştırmaya katılan öğretmenlerin yaklaşık \%70'i 10 yıl ve üzeri kıdeme sahiptirler.

Araştırmaya katılan öğretmenlerin cinsiyet değişkenine göre kıdem dağılımları Tablo 3 'te gösterilmektedir.

Tablo 3. Araştırmaya Katılan Öğretmenlerin Cinsiyet Değişkenine Göre Kıdem Dağılımları

\begin{tabular}{|c|c|c|c|c|}
\hline Cinsiyet & Kidem & $X$ & Ss & $\mathbf{N}$ \\
\hline \multirow[t]{5}{*}{ Kadın } & 1-5 Yil & 12,5000 & 5,27201 & 18 \\
\hline & 6-10 Yil & 13,6500 & 4,56848 & 20 \\
\hline & $11-15 Y_{11}$ & 12,6667 & 3,87298 & 27 \\
\hline & 16 Y1l ve üzeri & 12,4255 & 5,19927 & 47 \\
\hline & Toplam & 12,7143 & 4,76932 & 112 \\
\hline \multirow[t]{5}{*}{ Erkek } & $1-5 Y_{11}$ & 10,5000 & 6,35085 & 4 \\
\hline & 6-10 Y1l & 16,2000 & 4,49444 & 5 \\
\hline & 11-15 Y1l & 11,7500 & 5,72588 & 8 \\
\hline & 16 Yil ve üzeri & 14,0000 & 5,11604 & 24 \\
\hline & Toplam & 13,4878 & 5,32974 & 41 \\
\hline \multirow{5}{*}{$\begin{array}{l}\text { Cinsiyet (Top- } \\
\text { lam) }\end{array}$} & $1-5 Y_{11}$ & 12,1364 & 5,37450 & 22 \\
\hline & 6-10 Y 11 & 14,1600 & 4,57967 & 25 \\
\hline & $11-15 Y_{1 l}$ & 12,4571 & 4,28639 & 35 \\
\hline & $16 Y_{11}$ ve üzeri & 12,9577 & 5,18910 & 71 \\
\hline & Toplam & 12,9216 & 4,91979 & 153 \\
\hline
\end{tabular}

Araştırmaya katılan kadın öğretmenlerin 18'i 1-5 yıl; 20'si 6-10 yıl;27'si 11-15 yıl ve 47'si 16 yıl ve üzeri kıdeme sahiptir. Araştırmaya katılan erkek öğretmenlerden 4'ü 1-5 yıl; 5'i 6-10 yıl; 8'i 11-15 yıl ve 24'ü 16 yıl ve üstü kıdeme sahiptir. Araştırmaya katılan öğretmenlerin toplamda 22'si 1-5 yıl; 25'i 6-10 yıl; 35'i 11-15 yıl ve 71'i 16 yıl ve üstü kıdeme sahiptirler.

Ölçeğin birinci maddesinin ortalama puanı 3,36; ikinci maddesinin ortalama puanı 3,31; üçüncü maddesinin ortalama puanı 3,26 iken dördüncü maddesinin ortalama puanı 2,99 'dur (Tablo 4). Araştırmada yer alan öğretmenler birinci, ikinci, üçüncü ve dördüncü maddeye orta düzeyde katılmaktadır. 
Tablo 4. Birey-Örgüt Uyumu Ölçeği'nin Madde Bazında Ortalama Puan( $x$ ) ve Standart Sapma ( ss ) Değerleri

\begin{tabular}{lll}
\hline Ölçek Maddeleri & $\overline{\mathbf{x}}$ & Ss \\
\hline $\begin{array}{l}\text { Kişisel değerlerimin kurumun değerleriyle uyumlu olduğunu dü- } \\
\text { şünüyorum. }\end{array}$ & 3,36 & 1,306 \\
$\begin{array}{l}\text { Bu kurum insanlara bakış hususunda benimle aynı değere sahip- } \\
\text { tir. }\end{array}$ & 3,31 & 1,279 \\
Bu kurum dürüstlük konusunda benimle aynı değere sahiptir. & 3,26 & 1,317 \\
Bu kurum adalet konusunda benimle aynı değere sahiptir. & 2,99 & 1,449 \\
Birey-Örgüt Uyumu Ölçeği( Toplam) & 3,23 & 1,337 \\
\hline
\end{tabular}

Tablo 1'de yer alan değerlendirme aralığına göre sınıf öğretmenlerinin birey-örgüt uyumu konusundaki görüşlerinin 'orta düzeyde katılıyorum' yönünde olduğu görülmektedir (Tablo 4).

Sınıf öğretmenlerinin birey-örgüt uyumu görüsslerinin cinsiyete göre ortalama puanları ve her puana ait standart sapma değerleri Tablo 5 'te yer almaktadır.

Tablo 5. Sını Öğretmenlerinin Birey-Örgüt Uyumu Konusundaki Görüşlerinin Madde Bazında Cinsiyet Değişkenine Göre İncelenmesi

\begin{tabular}{|c|c|c|c|c|}
\hline Ölçek Maddeleri & Cinsiyet & $\mathbf{n}$ & $\bar{x}$ & ss \\
\hline Kişisel değerlerimin kurumun değerleriyle & Kadın & 112 & 3,36 & 1,279 \\
\hline uyumlu olduğunu düșünüyorum. & Erkek & 41 & 3,37 & 1,392 \\
\hline Bu kurum insanlara bakış hususunda benimle aynı & Kadın & 112 & 3,27 & 1,237 \\
\hline değere sahip. & Erkek & 41 & 3,41 & 1,396 \\
\hline Bu kurum dürüstlük konusunda benimle aynı de- & Kadın & 112 & 3,20 & 1,321 \\
\hline ğere sahip. & Erkek & 41 & 3,44 & 1,305 \\
\hline Bu kurum adalet konusunda benimle aynı değere & Kadın & 112 & 2,89 & 1,404 \\
\hline sahip. & Erkek & 41 & 3,27 & 1,550 \\
\hline Toplam & Kadın & 112 & 3,17 & 1,19 \\
\hline & Erkek & 41 & 3,37 & 1,33 \\
\hline
\end{tabular}

Tablo 1'de yer alan ortalama puan aralıkları göz önünde bulundurulduğunda kadın öğretmenler ölçeğin birinci maddesinde yer alan "kişisel değerler"; ikinci maddesinde yer alan "insanlara bakış", üçüncü maddesinde yer alan "dürüstlük" ve dördüncü maddesinde yer alan "adalet' konularına orta düzeyde katılırlarken; erkek öğretmenler ikinci maddede yer alan "insanlara bakış" ve üçüncü madde de yer alan "dürüstlük" konularına çoğunlukla; birinci ve dördüncü maddede yer alan 'kişisel değerler" ve "adalet" konularına orta düzeyde katıldıklarını belirtmişlerdir. 
Erkek öğretmenlerin, birinci ve dördüncü maddede yer alan ifadelere orta düzeyde katılmaları, bu konuda kadın öğretmenler gibi düşündüklerinı göstermektedir (Tablo 5).

Öğretmenlerin Birey-Örgüt Uyumu ile ilgili görüşlerinin cinsiyet ve k1deme ilişkin iki yönlü varyans analizi yapılmıştır. Yapılan analizin sonuçları Tablo 6'da bulunmaktadır.

Tablo 6. Öğretmenlerin Birey-Örgüt Uyumu İle İlgili Iki Yönlü Varyans Analizi Sonuçları

\begin{tabular}{|c|c|c|c|c|c|c|}
\hline Kaynak & $\begin{array}{l}\text { Kareler } \\
\text { toplamı }\end{array}$ & $\begin{array}{l}\text { Serbest- } \\
\text { lik de- } \\
\text { recesi }\end{array}$ & $\begin{array}{l}\text { Kareler ortala- } \\
\text { ması }\end{array}$ & $\mathbf{F}$ & $\mathbf{P}$ & $\eta^{2}$ \\
\hline Cinsiyet & 1,869 & 1 & 1,869 & 077 & 782 & 001 \\
\hline Kidem & 106,867 & 3 & 35,622 & 1,461 & 228 & ,029 \\
\hline Cinsiyet ${ }^{*}$ Kıdem & 65,617 & 3 & 21,872 & 897 & ,444 & ,018 \\
\hline Toplam & 3535,839 & 145 & 24,385 & & & \\
\hline
\end{tabular}

${ }^{*} \mathrm{p}<0.05$

Sınıf öğretmenlerinin birey-örgüt uyumu düzeylerinin cinsiyet ve k1deme göre istatistiksel olarak farklılık gösterip göstermediğini ortaya koymak amacıyla yapılan iki yönlü varyans analizi (two-way ANOVA), hem cinsiyet hem de kıdeme göre öğretmenlerin birey-örgüt uyumlarının 0,05’lik anlamlılık düzeyinde anlamlı bir farklılık göstermediğini ortaya koymuştur. Birey-örgüt uyumu konusunda cinsiyet değişkenine göre kadın ve erkek öğretmenlerin görüşleri arasında anlamlı bir fark bulunama-

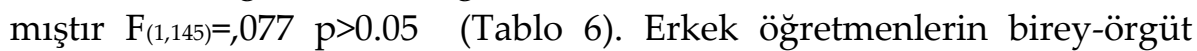
uyumu konusundaki görüşleri $(\bar{x}=3,37)$ ile kadın öğretmenlerin $(\bar{x}=3,17)$ birey-örgüt uyumu konusundaki görüşleri birbirine yakın değerlerdir (Tablo 5). Sınıf öğretmenlerinin birey-örgüt uyumu konusundaki görüşlerinin kıdem değişkenine göre farklılaşıp farklılaşmadığını belirlemek için yapılan iki yönlü varyans analizinde, öğretmenlerin kıdem sürelerine göre birey-örgüt uyumu konusundaki görüşlerinin $\mathrm{F}_{(3,145)=}=1,461 \mathrm{p}>0.05$ anlamlı bir fark göstermediği tespit edilmiştir (Tablo 6).

Cinsiyet bağımsız değişkeninin öğretmenlerin birey-örgüt uyumu puanları ve kıdem değişkeninin üzerindeki büyüklügünü test etmek için hesaplanan eta kare ( $\eta 2)$ değerlerine göre, birey-örgüt uyumu konusunda öğretmenlerin cinsiyetlerinin $(\eta 2=0,01)$ ve k1dem değişkeninin $(\eta 2=0,029)$ çok düşük düzeyde etkiye sahip olduğu belirlenmiştir. Varyans analizi 
hesaplamaları cinsiyet ve kıdem düzeyi arasında istatistiksel olarak önemli bir etkileşimin olmadığını göstermiştir. Bu ise farklı kıdem sürelerine sahip öğretmenlerin birey-örgüt uyumunun cinsiyet değişkeninden etkilenmediği anlamına gelmektedir (Tablo 6).

\section{Tartışma}

Birey-örgüt uyumu, işgörenin örgütte başarılı ve mutlu olmasının ya da mutsuz ve ayrılma niyetinde olmasının belirlenmesinde önemli bir araçtır. Ayrıca işgören ve örgüt arasındaki ilişkinin anlaşılması konusunda araştırmacılara ve yöneticilere yardımcı olmaktadır (İlkim, 2017). Bu araştırmada sınıf öğretmenlerinin birey-örgüt uyumu konusunda görüşleri incelenmiş ve elde edilen veriler analiz edilmiştir.

Araştırmaya katılan sınıf öğretmenlerinin birey-örgüt uyumu konusundaki görüşlerinin ortalama puanları alındığında sınıf öğretmenlerinin birey-örgüt uyumlarını sağladıklarına ilişkin görüşlerinin 'orta düzeyde katılıyor' olduğu görülmektedir. Ölçeğin dört maddesi ayrı ayrı ele alındığında erkek sınıf öğretmenleri insanlara bakış ve dürüstlük maddelerine çoğunlukla katıldıklarını; kişisel değerler ve adaletle ilgili maddelere ise orta düzeyde katıldıklarını belirtmişlerdir. Kadın sınıf öğretmenleri ise ölçeğin tüm maddelerine orta düzeyde katılmıştır. Yücel ve Çetinkaya (2016) birey-örgüt uyumunun güven, bağlllık, verimlilik, örgütsel vatandaşlık gibi olumlu; birey-örgüt uyumsuzluğunun ise stres, çatışma, işgören devri, yabancılaşma, devamsızlık, umursamazlık, işten çıkma/çıarılma gibi olumsuz şekilde sonuçlandığını belirtmiştir. Alparslan ve diğerleri (2015)'ne göre işgörenler, kendi özellikleri ile benzerlik derecesi yüksek olan örgütlerde kendilerini daha iyi hissedeceklerinden, bu tür örgütlere katılmayı ve bu tür örgütlerde kalmayı istemektedir. Olumlu ve olumsuz sonuçlar göz önünde bulundurulduğunda, birey- örgüt uyumunun sağlanmasının bireysel ve örgütsel açıdan önemli olduğu görülmektedir. Eğitsel açıdan ele alındığında; birey-örgüt uyumunun sağlanmasının öğretmenlerin güvende hissetmelerini, kuruma bağlılıklarının ve verimlerinin artmasını sağlayacağı ve bu olumlu sonuçların eğitimin kalitesini olumlu yönde etkileyeceği ileri sürülebilir.

Alanyazında yer alan, birey-örgüt uyumunun farklı örgütsel alan ve konularla olan ilişkisinin incelendiği çalışmalarda, araştırmacıların birey 
örgüt uyumu konusunda ulaştığ1 çeşitli sonuçlar görülmektedir. Köksal (2017) yaptığı araştırmada dağıtılan adalet algısının örgütsel bağl1lığı etkilediğini ve bu ilişkide kişi örgüt uyumunun aracılık etkisi yaptığını; Özgen ve Turunç (2017) örgütsel adaletin birey-örgüt uyumu üzerinde anlamlı ve pozitif etkisinin olduğunu tespit ederken; Kanbur (2017) ise psikolojik güçlendirme ile örgütsel özdeşleşme ve birey-örgüt uyumu arasında pozitif ve anlamlı bir ilişki olduğunu belirlemiştir. Bunların yanı sıra Ulutaş ise (2011) birey-örgüt uyumu ile verimlilik arasında pozitif yönde anlamlı ve güçlü bir ilişki olduğu sonucuna ulaşmıştır. Çeşitli ve değişik konularla ilişkilendirilmesi, birey-örgüt uyumunun farklı değişkenleri etkilediği ve farklı değişkenlerden etkilendiğini göstermektedir. Bu duruma göre, öğretmenlerin de eğitim kurumu olan okullara uyumunun farklı değişkenlerden etkileneceği ve farklı değişkenleri etkileyeceği ifade edilebilir.

\section{Sonuç}

Bu araştırmada birey-örgüt uyumu cinsiyet ve kıdem değişkenlerine göre ele alınmıştır. Araştırmaya katılan öğretmenlerin birey-örgüt uyumu konusundaki görüşlerinin cinsiyet ve kıdeme göre anlamlı bir farklılık göstermediği sonucuna ulaşılmıştır. Birey örgüt uyumu konusunda çalışmak isteyen araştırmacılara ilkokul, ortaokul ve liselerde görev yapan öğretmenlerin birey-örgüt uyumu konusundaki görüşlerinin incelenmesi; yine devlet okullarında ve özel okullarda görev yapan branş öğretmenleri ile sinıf öğretmenlerinin birey-örgüt uyumu konusundaki görüşlerinin araştırılması önerilebilir. 


\title{
EXTENDED ABSTRACT
}

\section{A Research on Person-Organization Fit of Primary School Teachers}

\author{
Volkan Sarıboğa - Elife Doğan Kılıç - Hüseyin Serin \\ Ministry of National Education - Istanbul University Cerrahpaşa
}

One of the main objectives of modern organizations is the adaptation of employees to work and organization. Individual, organizational and social contributions of employees who adapt to the environment they live in are increasing (VanVianen, et al., 2007). In organizations, during the recruitment process, it is taken care to select individuals who can adapt to the organization. In the same way, orientation programs are organized for newly recruited individuals and socialization of new employees is targeted (Kesen, 2017). Organizational socialization is a process in which newly recruited employees learn the necessary technical skills to comply with rules, norms, culture, organizational roles and other roles of the organization they are participating in. An organization that has adapted to the basic goals of its employees benefits from positive results such as productivity. In the case of non-adaptation, increased job stress in employees can lead to inefficiency, which can be a major obstacle to the organization's achievement of its objectives (Ulutaş, 2011). Schneider (1987) asserts that individuals feel more comfortable in organizations which have similar individuals with them. For this reason, individuals are more willing to participate in such organizations.

Person-organization fit is defined in various ways by researchers. While Chatman (1989) defines person-organization fit as the harmony between organizational norms and values and individuals' values, Kristof (1996) defines person-organization fit as "the conformity of the individual's expectation, desire, personal values and goals to the organization's value, purpose and system". According to Andrews, Baker and Hunt (2011) person-organization fit is a harmony between individual's personality, values, aims, attitudes and organizational culture, values, goals and norms. Schneider (1987) argues in Attraction- Selection -Attrition (ASA) 
theory that individuals tend to participate in organizations that appropriate to their own values, needs and personality. This view has something in common with Chatman's (1989) and Kristof's (1996) views on personorganization fit. Chatman's definition of person-organization fit as conformity between personal values and organizational values and norms, and Kristof's emphasis on the concept of value in a similar way shows that values have an important function in providing person-organization fit.

In Schneider (1987)'s ASA theory, the first fundamental element of providing person-organization fit is the harmony of individual and organizational values. Cultural elements that affect individuals' thoughts, attitudes and behaviors are called 'value' (Fidan, 2009). There are two types of values in ASA theory: personal and organizational values. Personal values are the principles or beliefs that are believed to be true by the members in general and reflect the thoughts, goals and emotions of a community in order to maintain its unique existence, unity and continuity (Demirci ve Aydemir, 2006). Organizational values express generally accepted situations and behaviors in the organization (Chatman, 1991). Organizational values are evaluative standards related to work or work environment in which employees realize the truth or predict the importance of preferences and results (Vurgun ve Öztop, 2011). The harmony of personal values with organizational values is effective in determining the quality of the work behaviors of employees (Kılıç, 2010). In ASA theory, the second basic element of providing person-organization fit is needs. Personal needs and organizational needs are essential to determine the harmony. Maslow (1970), Herzberg (1982), Alderfer (Newstorm ve Keith, 1997), McClelland (Hodgetts ve Luthans, 1994) provide various theories about personal needs and these theories claim various ideas about the personal needs. For example, according to Maslow's Hierarchy of Needs theory, meeting the needs of the individual follows a certain sequence. Needs in the hierarchy are listed bottom to top as 'physiological needs, safety needs, love and belonging, esteem and self-actualization (Hoy ve Miskel, 2013). According to this theory, it is possible for a person to move to a higher-level needs by satisfying needs of the lower level sufficiently (Kula ve Çakar, 2015). Organizational needs include organizational commitment, diligence, employee collaboration, creativity, adherence to orders, quality work, commitment to organizational goals, friendship with other employees, respect for 
authority and employee satisfaction (Ulutaş, 2011). The third underlying element of providing the person-organization fit for ASA is the congruence of personal and the organizational characteristics. Personal characteristic can be defined as the totality of mental, physical and functional characteristics that differentiate individual from others and can be observed in the social relations dimension (Soysal, 2008). In addition to the characteristics of a person, an organization also has unique characteristics (Bursalığlu, 2015). To sum up, according to the ASA congruence between personal and organizational values, needs and characteristics are significant for person-organization fit.

The purpose of this research is to determine the views of primary school teachers on person-organization fit. The population of the research consists of primary school teachers who work in Bağcllar district of İstanbul. The sample of the research is composed of 153 volunteer primary school teachers who were randomly selected from the population. The research has two limitations. Firstly, the research is limited to the opinions of the primary school teachers who work in schools of Bağcllar district of İstanbul. Secondly, the research is limited to the data and situations obtaining in the 2018-2019 school year. In the research, the scale of 'PersonOrganization Fit' which was developed by Netemeyer et al. (1997) and adapted to Turkish by Turunç and Çelik (2012) was used. The scale of 'Person-Organization Fit' consists of 4 items. The first item is about values, the second item is about concern for others, the third item is about honesty and the fourth item is about justice. The Cronbach alpha value of the scale was determined as 0,94 . The data obtained from the person-organization fit scale were statistically analyzed. Two-way ANOVA was used to determine whether person-organization fit showed a significant difference in teachers' views according to gender and seniority variables. Before the analysis, such variance analysis assumptions were tested as whether the data were normally distributed for each subgroup and whether the variances were homogeneous between the groups. Levene test was used to determine whether the data were normally distributed or not.

As a consequence, the research results showed that primary school teachers' views about person- organization fit were at a medium level. When examined in terms of gender variable, it was found that female primary school teachers' opinions about person-organization fit were at a 
medium level in all of the four items of the scale. Male primary school teachers' opinions about person-organization fit were at a medium level in scale's first and fourth items. In second and third items male primary school teachers' views were at a higher level than the female primary school teachers' views. According to this situation, female teachers were at a medium level but male teachers mostly agreed with the views that were stated in the second and third items. It was examined whether person-organization fit showed a significant difference in teachers' views according to gender and seniority variables. The research results indicated that the opinions of primary school teachers about person-organization fit did not show a significant difference according to gender and seniority variables.

\section{Kaynakça / References}

Alparslan, M.A., Çiçek, H. ve Soydemir, S. (2015). Birey-örgüt uyumunu güçlendiren öncül: İşyeri arkadaşlığı. Akdeniz İ.I.B.F.32, 175-194.

Andrews, M.C, Baker, T. ve Hunt, T.G. (2011). Values and person-organization fit: Does moral intensity strengthen outcomes? Leadership ve Organization Development Journal, 32(1), 5-19.

Baysal, A. C. (1985). Birey-örgüt bütünleşmesinde davranışsal yaklaşımlar. İstanbul Üniversitesi İşletme Fakültesi Dergisi, 14(1), 63-83

Boxx, W. R., Odom, R. Y. ve Dunn, M. G. (1991). Organizational values and value congruency and their impact on satisfaction, commitment, and cohesion: An empirical examination within the public sector. Public Personnel Management, 20(2), 195-205.

Bursalığlu, Z. (2015). Okul yönetiminde yeni yapı ve davranış. Ankara: Pegem Akademi.

Büyüköztürk, Ş. (2006). Sosyal bilimler için veri analizi el kitabı. Ankara: Pegema Yayıncilik.

Chatman, J. (1989), Improving Interactional organizational research: A model of person-organization fit. Academy of Management Review, 14, 333-349.

Chatman, E. A. (1991). Life in a small world: Applicability of gratification theory to information-seeking behavior. Journal of the American Society for information science, 42(6), 438.

Çalık, T. (2003). İşgörenlerin Örgüte Uyumu (Örgütsel Sosyalizasyon). Türk Eğitim Bilimleri Dergisi, 1(2), 163-177. 
Demirci, M.K. ve Aydemir, M. (2006). Örgütsel değerlerin işletmelerin sosyal sorumluluk anlayışlarını belirlemedeki rolü: Bursa ilinde gerçekleştirilen bir araştırma. Atatürk Üniversitesi İktisadi ve İdari Bilimler Dergisi, 20(2), 311-326.

Fidan, N. K. (2009). Öğretmen adaylarının değer öğretimine ilişkin görüşleri. Kuramsal Ĕ̆itimbilim Dergisi, 2(2), 1-18.

Fraenkel, J.R. ve Wallen, N.E. (2009). How to design and evaluate research in education. New York: McGraw-Hill.

Hodgetts, R. ve Luthans, F. (1994). International management. McGraw Hill Inc. Hoy, W.K. ve Miskel, C.G. (2013). Educational administration: Theory, research and practice. McGraw-Hill Higher Education.

İlkim, N.Ş. (2017). Birey-örgüt kavramı üzerine kavramsal bir inceleme. İnönü Üniversitesi Uluslararası Sosyal Bilimler Dergisi, 6(1).238-254

Kanbur, E. (2017). Psikolojik güçlendirme ve örgütsel özdeşleşme arasında birey-örgüt uyumunun aracı rolü. Uluslararası Sosyal ve Eğitim Bilimleri Dergisi, 4 (7), 63-82.

Kaplanoğlu, E. (2014). Mesleki stresin temel nedenleri ve muhtemel sonuçları: Manisa ilindeki SMMM'ler üzerine bir araştırma. Muhasebe ve Finansman Dergisi, Ekim Sayısı 131-150

Karasar, N.(2006). Bilimsel araştırma yöntemi. Ankara: Nobel Yayın Dağıtım.

Kesen, M. (2017). Birey-örgüt uyumunun duygusal emek üzerindeki etkileri: Hemşireler üzerine görgül bir araştırma. Süleyman Demirel Üniversitesi Vizyoner Dergisi, 8(18), 75-89.

Kılıç, K. C. (2010). Bireysel ve örgütsel değerler arasındaki uyumun çalışanların iş davranışlarına etkileri üzerine ampirik bir çalışma. Ç.Ü. Sosyal Bilimler Enstitüsü Dergisi, 19(1), 20-35.

Köksal, K. (2017). Kişi-örgüt uyumunun örgütsel adalet algıSı ve örgütsel bağlılık ilişkisinde aracilık rolü. Savunma Bilimleri Dergisi, 16(2), 21481776.

Kristof, A.L. (1996). Person-organization fit: an integrative review of its conceptualizations, measurement and implications. Personnel Psychology, 49(1), 1-49.

Kula, S. ve Çakar, B. (2015). Maslow ihtiyaçlar hiyerarşisi bağlamında toplumda bireylerin güvenlik algısı ve yaşam doyumu arasındaki ilişki. Bartı Üniversitesi I.I.̇.B.F. Dergisi, 6(12), 191-210.

Maslow, A. (1970). Motivation and Personality. New York: Harper and Row. 
Netemeyer, R.G., Boles, J.S., MacKee, D.O. ve MacMurrian, R. (1997) An investigation into the antecedents of organizational citizenship behaviours in a personal selling context. Journal of Marketing, 61, 85-98.

Newstorm J. ve Keith, D. (1997). Organzational behavior, human behavior at work. McGraw Hill Inc.

Özdamar, K. (2013). Paket programlarla istatistiksel veri analizi. Eskişehir: Nisan Yayinevi.

Özgen, F.Ö. ve Turunç, Ö. (2017). Örgütsel adalet- sinizm ilişkisinde kişi örgüt uyumunun rolü: eğitim sektöründe bir araştırma. Uluslararası İktisadi ve İdari Bilimler Dergisi, 3(2),80-96.

Özkalp E. ve Kırel Ç. (2001). Örgütsel davranış. Anadolu Üniversitesi Ĕ̆itim, Sağlık ve Bilimsel Araştırma Çalışmaları Vakfı, Yayın No:149, Eskişehir.

Rynes, S. L., Brown, K. G. ve Colbert, A. E. (2002). Seven common misconceptions about human resource practices: Reesearch fidings versus practitioner beliefs. Academy of Management Executive, 16(3), 92-103.

Schneider, B. (1987). The people make the place. Personnel Psychology, 40 (3), 437-453.

Song, Z., ve Chathoth, P. K. (2011). Intern newcomers' global self-esteem, overall job satisfaction, and choice intention: Person-organization fit as a mediator. International Journal of Hospitality Management, 30(1), $119-128$.

Soysal, A. (2008). Çalışma yaşamında kişilik tipleri: bir literatür taraması. Çimento İşveren Dergisi, Ocak. 4-19 İnd. Tarihi: 05.01.2019. http://www.ceis.org.tr/dergiDocs/makale129.pdf

Şerefhanoğlu, O. (2014). Okul müdürlerinin mentorluk fonksiyonları ile öğretmenlerin örgütsel uyum düzeyleri arasındaki ilişki: Balıkesir ili örneği. Yayımlanmamış yüksek lisans tezi. Balıkesir Üniversitesi Sosyal Bilimler Enstitüsü.

Turunç, Ö. ve Çelik, M. (2012). İş tatmini-kişi-örgüt uyumu ve amire güvenkişi-örgüt uyumu ilişkisinde dağıtım adaletinin düzenleyici rolü. İş, Güç Endüstri İlişkileri ve İnsan Kaynakları Dergisi, 14(2).57-78.

Tutar, H. (2014). Örgütsel psikoloji: Endüstri ve örgüt psikolojisine yeni yaklaşımlar. Ankara: Detay Yayıncılık.

Ulutaş, M. (2011). Birey-örgüt uyumunun iş stresi ve verimlilik üzerine etkisi: Dalaman Havalimanı çalışanları üzerine bir alan araştırması. Selçuk Üniversitesi Meslek Yüksekokulu Dergisi, 4, 1-2.

Ulutaş, M. (2011). Harmonik yönetim. Konya: Ulvita Yayıncılık. 
Ulutaş, M., Kalkan, A. ve Bozkurt, Ö.Ç. (2015). Birey-örgüt uyumunun iş doyumu ve örgüte bağlllık üzerine etkisi. İş, Güç Endüstri İlişkileri ve İnsan Kaynakları Dergisi, 17(1), 2148-9874.

VanVianen, A. (2001). Person-Organization fit: The match between theory and methodology: Introduction to the special issue. Applied psychology: an international review, 50 (1), 1-4.

Van Vianen, A.E.M., De Pater, I.E. ve Van Dijk, F. (2007). Work value fit and turnover intention: samesource or different-source fit. Journal of Managerial Psychology, 22(2), 188-202.

Vilela, B. B., González, J. A. V. ve Ferrín, P. F. (2008). Person-organization fit, $\mathrm{OCB}$ and performance appraisal: Evidence from matched supervisorsalesperson data set in a Spanish context. Industrial Marketing Management, 37(8), 1005-1019.

Vurgun, L. ve Öztop, S. (2011). Yönetim ve örgüt kültüründe değerlerin önemi. Süleyman Demirel Üniversitesi İktisadi ve İdari Bilimler Fakültesi Dergisi, 16(3): 217-230.

Yıldız, M.L. (2013). Algılanan kişi-örgüt uyumu, tanınırlık, imaj, örgütsel çekicilik ve işe başvurma niyeti arasındaki ilişkilerin yapısal eşitlik modellemesi ile incelenmesi. Marmara Üniversitesi I.I.I.B.Dergisi, XXXIV(I), 153-173.

Yücel, İ. ve Çetinkaya, B. (2016). Birey-örgüt uyumu ile örgütsel bağlllık arasındaki ilişkide cinsiyetin rolü: Kayseri örneği. Aksaray Üniversitesi İktisadi ve İdari Bilimler Fakültesi Dergisi, 8 (3), 17-30.

\section{Kaynakça Bilgisi / Citation Information}

Sarıboğa, V., Kılıç, E. ve Serin, H. (2019). Sınıf öğretmenlerinin birey-örgüt uyumu üzerine bir araştırma. OPUS-Uluslararası Toplum Araştırmaları Dergisi, 13(19), 95-115. DOI: 10.26466/opus.567443 